\title{
Bilateral temporomandibular joint dislocation after upper gastrointestinal endoscopy in an intensive care unit patient: a rare complication
}
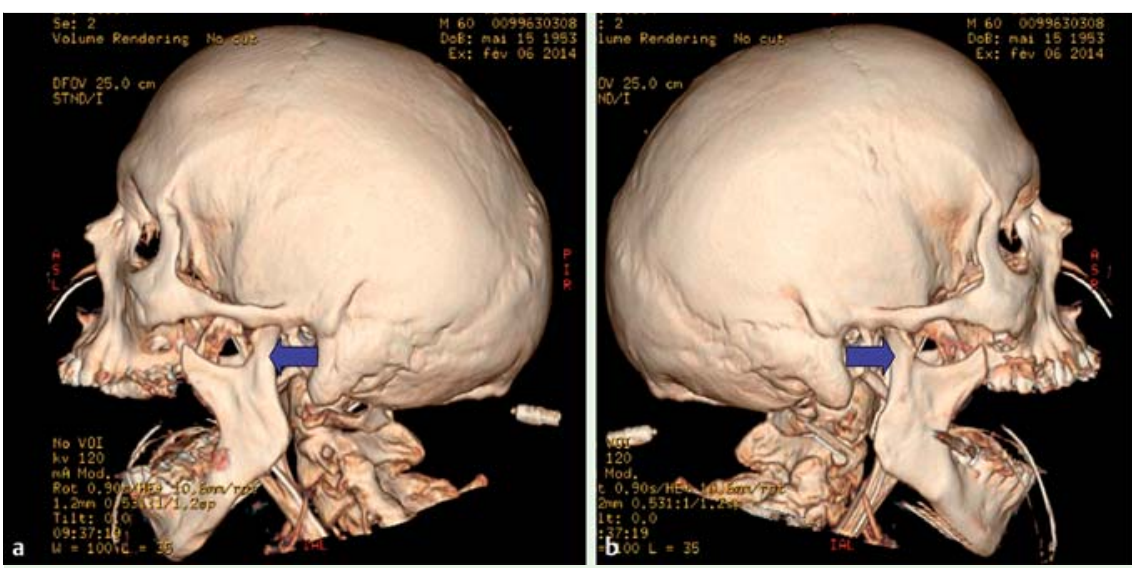

Fig. 1 Facial computed tomography $(\mathrm{CT})$ scan with 3D reconstruction in a 60-year-old man after upper gastrointestinal endoscopy. On both sides, emptiness of the mandibular fossa, anterior mandibular condyle displacement (blue arrow), and dental asymmetry can be seen. a Left side; b right side.

A 60-year-old man, without dental articulation disorders or a history of dislocation of the temporomandibular joint, was admitted to our intensive care unit after surgery for aortic dissection. He had been intubated without complication 4 days earlier. On the day of surgery, he was sedated with midazolam and sufentanyl, and received a neuromuscular blocker. Using a flexible endoscope, upper gastrointestinal endoscopy to rule out gastrointestinal bleeding was performed without technical difficulty. Immediately afterwards, examination demonstrated an inability to close the mouth and emptiness of the mandibular fossa. Bilateral temporomandibular joint dislocation (TMJD) was diagnosed and was corrected temporarily using the Nélaton maneuver. A subsequent computed tomography (CT) scan ruled out a fracture of the mandibular $\operatorname{arch}(\bullet$ Fig. 1).

Complications after upper gastrointestinal endoscopy are scarce (9\%) [1]. TMJD is defined as the permanent loss of the normal articular relationship between the temporal eminence and mandibular condyle. The head of the mandibular condyle passes in front of the temporal eminence and cannot return to the glenoid cavity because of protrusion of the temporal eminence and contraction of the masseter muscles. Risk factors for TMJD are a history of dislocations or subluxations of the temporomandibular articulation, occlusal mandibular disorders, and ligament laxity. To the best of our knowledge, only a few TMJDs have been reported after upper gastrointestinal endoscopy in ambulant patients [2-5]. We report the first case in a patient intubated orotracheally and on prolonged sedation. Proposed risk factors for TMJD during endoscopy include general anesthesia, a hard inflexible mouthpiece, or a history of TMJD $[3,6,7]$. Here, the use of sedative drugs and neuromuscular blockers probably contributed to it, secondarily to increased laxity. The presence of an endotracheal tube may also exert a downward pressure on the mandible and extend a forced opening of the jaw. When endoscopy is performed on sedated and paralyzed patients, this complication may go undetected. TMJD must be corrected quickly, before the masseter muscle spasm worsens. After a failed correction, a mandibular fracture should be suspected and a CT scan performed [8].

Endoscopy_UCTN_Code_CPL_1AH_2AJ

Competing interests: None

\section{Diane Lorenzo, Florence Boissier, Alexandra Prost, Claire Gallois, Christophe Faisy}

Service de Réanimation Médicale, Hôpital Européen Georges Pompidou, AssistancePublique-Hôpitaux de Paris, Paris, France

\section{References}

1 Zubarik R, Eisen G, Mastropietro C et al. Prospective analysis of complications 30 days after outpatient upper endoscopy. Am J Gastroenterol 1999; 94: 1539-1545

2 Lacy PD, Lee JM, O'Morain CA. Temporomandibular joint dislocation: an unusual complication of upper gastrointestinal endoscopy. Am J Gastroenterol 2000; 95: $3653-$ 3654

3 Mangi Q Ridgway PF, Ibrahim Z et al. Dislocation of the mandible. Surg Endosc 2004; 18: $554-556$

4 Nijhawan S, Nepalia S. Dislocation of temporomandibular joint after upper gastrointestinal endoscopy. Trop Gastroenterol 1994; 15: 232

5 Savas MC, Gulsen MT, Kadayifci A. Habitual dislocation of the temporomandibular joint during upper endoscopy. Gastrointest Endosc 2004; 60: 325

6 Sayilir A, Kurt M, Kacar $S$ et al. Dislocation of the temporomandibular joint during upper endoscopy without sedation. Endoscopy 2009; 41: 818; author reply 818

7 Min B-H, Lee H, Jeong JS et al. Comparison of a novel teeth-protecting mouthpiece with a traditional device in preventing endoscopyrelated complications involving teeth or temporomandibular joint: a multicenter randomized trial. Endoscopy 2008; 40: 472-477

8 Akinbami BO. Evaluation of the mechanism and principles of management of temporomandibular joint dislocation. Systematic review of literature and a proposed new classification of temporomandibular joint dislocation. Head Face Med 2011; 7: 10

\section{Bibliography}

DoI http://dx.doi.org/

10.1055/s-0034-1377635

Endoscopy 2014; 46: E538

(c) Georg Thieme Verlag KG

Stuttgart · New York

ISSN 0013-726X

\section{Corresponding author}

Diane Lorenzo, MD

Service de Réanimation Médicale

20 rue Leblanc

75015 Paris

France

Fax: +33-1-56093202

diane.lorenzo@gmail.com 